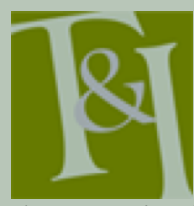

The International Journal for Translation \& Interpreting Research trans-int.org

\title{
Introduction: Translation of questionnaires in cross-national and cross-cultural research
}

\author{
Dorothée Behr \\ GESIS - Leibniz Institute for the Social Sciences, Mannheim (Germany) \\ dorothee.behr@gesis.org
}

\author{
Mandy Sha \\ Independent Consultant \\ mandy@mandysha.com
}

DOI: 10.12807/ti.110202.2018.a01

Translation of questionnaires has enabled cross-national and cross-cultural comparisons in the social sciences, psychology, quality-of-life research, education research, and business studies. Questionnaires are typically translated or adapted from a source language into one or several target language(s). Best practice includes parallel translation, team discussions, extensive quantitative and qualitative pretesting with respondents, and detailed documentation (Behr \& Shishido, 2016; Harkness, Villar, \& Edwards, 2010; Sha \& Pan, 2013). But these methods are still unfamiliar to many in translation studies and the translation industry. In addition, experts in the subject-matter disciplines may lack knowledge about the state of the art in translation research. To encourage interdisciplinary exchange, translation scholars have started to reconcile translation studies and the field of questionnaire translation by combining the latest theories, approaches, and findings from both fields (Behr, 2009; Bolaños-Medina \& González-Ruiz, 2012; Dorer, 2015; Kußmaul, 2007; Ozolins, 2009; Przepiórkowska, 2016).

This special issue is an organized effort to present research and practice in the field of questionnaire translation from rich perspectives. The authors in this special issue come from both scholarly and professional communities who represent various research traditions, disciplines, and generations. The articles reflect the diversity of challenges and research topics in the field of questionnaire translation (and even beyond, since we included the translation of assessment instruments and forms in this special issue). The first article by Behr provides an overall introduction to the topic of questionnaire translation. Her paper introduces the genre of questionnaires and particularities that come with translating such "research instruments". Using the categorization of translation competences from the ISO 17100 as a structuring device, she describes what makes questionnaire translation special and what needs to be heeded when translating this genre.

The next paper discusses concrete translation or adaptation challenges and opportunities, thus giving an idea of what is at stake when research instruments are not translated with the intended users in mind. Goerman, Fernández, and Quiroz focus on the translation/adaptation of educational 
attainment questions from English into Spanish for Spanish-speaking immigrants in the United States. Their article highlights both the challenges involved in trying to accommodate the different cultural backgrounds of Spanish speakers and the importance of using pretesting methods in the process of finalizing a questionnaire in the target language.

The following four articles provide insights into various translation and assessment methods and steps that are peculiar for the field of questionnaire translation - and more in general - for the translation and adaptation of research instruments. Various steps of the TRAPD best practice model are investigated in these articles, with TRAPD standing for Translation, Review, Adjudication, Pretesting, and Documentation (Harkness, 2003).

Curtarelli and van Houten reflect on the operationalization and implementation of a multi-step translation and assessment approach in the European Company Survey, which was modelled upon the TRAPD method. They describe the conditions that were either conducive or obstructive for the implementation of their approach, and summarize lessons learned for future surveys.

Upsing and Rittberger present translation quality control procedures in large-scale assessment studies, in particular in the OECD assessment studies PISA and PIAAC. Drawing on a qualitative interviewing study, they focus on how translators and other players in the translation process perceive and work with these quality control procedures. Pointers are provided as to how quality control procedures could be optimized in future surveys.

Mneimneh et al.'s article provides insights into cognitive interviewing, a much recommended pretesting method that explores how respondents actually understand and perceive survey questions. Using the Arabic version of the World Mental Health Survey instrument, the authors test different cognitive probes for assessing question sensitivity. This article shows that the social research toolbox is constantly evolving in general and in terms of its crosscultural applicability.

Son tackles the much-discussed method of back translation in crossnational and cross-cultural research. Instead of supporting or further advocating its use as a quality control method, she argues for its utility as a documentation tool - alongside explanatory prose of translation decisions. Thus, transparency across all the stages of multilingual questionnaire development can be increased. Son illustrates her argument with English/Korean and English/Chinese examples.

The final three articles show the breadth of the theme of the special issue. They discuss survey research among deaf signing communities, translation of patients' personal and medical information forms, and the role of translation and visual cues in facilitating entry to online survey questionnaires.

Napier and her co-authors discuss general challenges faced in conducting survey research with deaf signers. Furthermore, using the example of the Insign project - a multi-country study with deaf signers - they explore the advantages and disadvantages of using International Sign and also the general conditions and challenges of conducting such a study.

Gonzales-Darriba employs a genre approach based on English for Special Purposes and Discourse Analysis applied to Translation (Gamero, 2001; García Izquierdo, 2009) to analyze a corpus of Spanish translations of Patients' Personal and Medical Information Forms (PPMIF), as used in the United States. The findings are meant to raise awareness for this genre and inform translation training and assessment.

Sha, Hsieh, and Goerman find that combining translation with common website functionality visual cues (tabs, hyperlinks, drop-down menus, and URLs) could facilitate limited English speakers' entry to U.S. Federal government Internet surveys. They also provide recommendations for 
continued research to develop translations and visual cues that are visible, clear, and linguistically and culturally appropriate.

We hope that this special issue will encourage cross-fertilization and shared trust among disciplines to ignite questionnaire translation research. Continuous efforts are important because the results of cross-national and cross-cultural studies must be grounded in sound data collection methods, which rely heavily on questionnaire translation. Cross-national and crosscultural studies compare countries, cultures, or other groups across multiple dimensions, which contributes to our understanding of phenomena such as attitudes and opinions (e.g., towards democracy, family, or migration), personality, values, behavior (e.g., as regards health) or competencies (e.g. regarding reading or problem solving) (e.g. Smith, 2010; van de Vijver, 2013). Further collaboration, discussions, and developments in questionnaire translation will enhance the comparability of the data collected through questionnaires and ultimately the conclusions that are drawn from the data.

\section{References}

Behr, D. (2009). Translationswissenschaft und international vergleichende Umfrageforschung: Qualitätssicherung bei Fragebogenübersetzungen als Gegenstand einer Prozessanalyse. Bonn: GESIS. Retrieved from http://nbnresolving.de/urn:nbn:de:0168-ssoar-261259

Behr, D., \& Shishido, K. (2016). The translation of measurement instruments for cross-cultural surveys. In C. Wolf, D. Joye, T. W. Smith, \& Y. Fu (Eds.), The SAGE handbook of survey methodology (pp. 269-287). London: Sage.

Bolaños-Medina, A., \& González-Ruiz, V. (2012). Deconstructing the translation of psychological tests. Meta: Journal des Traducteurs / Meta: Translators' Journal, 57(3), 715-739.

Dorer, B. (2015). Carrying out 'advance translations' to detect comprehensibility problems in a source questionnaire of a cross-national survey. In K. Maksymski, S. Gutermuth, \& S. Hansen-Schirra (Eds.), Translation and comprehensibility (pp. 77-112). Berlin: Frank \& Timme.

Gamero, S. P. (2001). La traducción de textos técnicos. Barcelona: Ariel.

García Izquierdo, I. (2009). Divulgación médica y traducción: El género información para pacientes. Bern: Peter Lang.

Harkness, J. (2003). Questionnaire translation. In J. Harkness, F. J. R. van de Vijver, \& P. Ph. Mohler (Eds.), Cross-cultural survey methods (pp. 35-56). Hoboken, NJ: Wiley.

Harkness, J. A., Villar, A., \& Edwards, B. (2010). Translation, adaptation, and design. In J. A. Harkness, M. Braun, B. Edwards, T. P. Johnson, L. Lyberg, P. Ph. Mohler, ... \& T. W. Smith (Eds.), Survey methods in multinational, multiregional, and multicultural contexts (pp. 117-140). Hoboken, NJ: John Wiley and Sons.

Kußmaul, P. (2007). Risikomanagement beim Übersetzen sozialwissenschaftlicher Umfragen. In G. Wodjak (Ed.), Quo vadis Translatologie? Ein halbes Jahrhundert universitärer Ausbildung von Dolmetschern und Übersetzern in Leipzig (pp. 235-253). Berlin: Frank \& Timme.

Ozolins, U. (2009). Back translation as a means of giving translators a voice. Translation \& Interpreting, 1(2), 1-13.

Przepiórkowska, D. (2016). Translation of questionnaires in cross-national social surveys: A niche with its own theoretical framework and methodology. Między Oryginatem a Przekładem, 31, 121-135.

Sha, M., \& Pan, Y. (2013). Adapting and improving methods to manage cognitive pretesting of multilingual survey instruments. Survey Practice, 6(4), 1-8.

Smith, T. W. (2010). The globalization of survey research. In J. A. Harkness, M. Braun, B. Edwards, T. P. Johnson, L. Lyberg, P. Ph. Mohler, ... \& T. W. Smith (Eds.), Survey methods in multinational, multiregional, and multicultural contexts (pp. 477-487). Hoboken, NJ: John Wiley and Sons. 
van de Vijver, F.J .R. (2013). Contributions of internationalization to psychology: Toward a global and inclusive discipline. American Psychologist, 68(8), 761770. 